Comparative Philosophy Volume 6, No. 1 (2015): 129-148

Open Access / ISSN 2151-6014

www.comparativephilosophy.org

CONSTRUCTIVE ENGAGEMENT DIALOGUE (1.1)

\title{
WANG CHONG, TRUTH, AND QUASI-PLURALISM
}

\section{LAJOS L. BRONS}

The first century Chinese philosopher Wang Chong 王充 has largely escaped the attention of comparative philosophers. That this oversight is undeserved is shown by two journal articles and an encyclopedia entry by Alexus McLeod (2007; 2011; 2012). McLeod sketches an intriguing picture of a philosopher whose style and approach to philosophy reminds more of analytic philosophy than of popular images of Chinese philosophy. Wang Chong preferred clear and direct argument to the "flowery and artificial writing" (華偽之文) that he perceived to be customary in his day, ${ }^{1}$ adhered to a kind of metaphysical realism, and advocated a two-faced philosophical method of questioning (wen 問) what is unclear and challenging (nan 難) what is false or invalid. ${ }^{2}$

While McLeod deserves praise for making Wang Chong more accessible to a Western audience, I have my doubts about his analysis of Wang Chong's theory of truth as presented in this journal (see McLeod 2011). McLeod argues that Wang Chong implicitly adhered to a kind of pluralism about truth somewhat similar to the theories defended by Crispin Wright and Michael Lynch in the last two decades, and even improves on those by solving the problem of mixed discourse. In this response to McLeod, I want to challenge (aspects of) this interpretation of Wang Chong, and suggest a kind of "quasi-pluralism" that builds on both McLeod's pluralist interpretation and my critique thereof.

BRONS, LAJOS L.: Adjunct Professor of Philosophy, Lakeland College Japan Campus, and Researcher, Department of Philosophy, Nihon University, Tokyo, Japan. Email: mail@lajosbrons.net

\footnotetext{
${ }^{1}$ Some of Wang Chong's criticism of his contemporaries sound much like an analytic philosopher commenting on continental philosophy.

2 On Wang Chong's philosophical method, see McLeod (2007).
} 


\section{CONCEPTS AND THEORIES OF TRUTH}

In the introduction of his paper, McLeod (2011) remarks that the debate about concepts of truth in early Chinese philosophy is weighed down by (implicitly) assuming a correspondentist notion of truth. (And apparently this has led some to suggest that, lacking a correspondentist theory of truth, the ancient Chinese were lacking the concept of truth altogether.) I'm insufficiently familiar with that debate to judge whether he is right, but I certainly agree with him that the debate should not be weighed down by assuming one or another specific theory of truth (or even multiple theories).

There is a difference between the concept of truth and a theory of truth. One can have a concept of truth without having a theory of truth, but (obviously) not the other way around. One can even have the concept of truth without having a (or one single) word for it. Having the concept of truth is having the concepts of objectivity, falsehood, error, and mistake; it is understanding that there is a difference between what is the case and what is not. In a number of papers from the 1980s and 1990s, Donald Davidson argued that propositional thought is impossible without the concept of truth. ${ }^{3}$ If Davidson is right, then it would be impossible for the early Chinese to not have the concept of truth. That having the concept of truth does not imply having a theory of truth is illustrated by Davidson himself. Davidson defended a version of primitivism: "truth is as clear and basic a concept as we have" $(2001,155)$ and the search for a theoretical definition of the notion is mistaken, or a "folly" (2005a, 201). ${ }^{4}$ (Although this implies that primitivism is not a theory of truth-rather, it claims that there cannot be a theory of truth - I will use the term 'theory of truth' loosely in the following to include primitivist theories about truth.)

The view that the search for a theoretical definition of truth is mistaken is shared by deflationism, which is sometimes overlooked in overviews of the debate about truth framed in terms of the correspondentism - coherentism - pragmatism triad, but that triad is about a century out of date. The two main parties in the contemporary debate are correspondentism (including a number of variants and offshoots) and deflationism. ${ }^{5}$ The old, idealist coherentism disappeared from the scene a long time ago. A few new forms of coherentism have been proposed in the last quarter of the

\footnotetext{
${ }^{3}$ Most of these papers can be found in Subjective, Intersubjective, Objective (Davidson 2001); see especially chapters 7,9 , and 14 .

4 This does not imply that 'true' doesn't have a lexical definition capturing how we normally use the term and reflecting our pre-theoretical understanding of truth. Davidson used different terms on different occasions to characterize this pre-theoretical understanding, often relying on phrases like "capturing the way things are / the world is". On Davidson's primitivism, see his (2001), chapter 10 and "Afterthoughts", and (2005a), chapters 1 and 2.

${ }^{5}$ The aforementioned primitivism about truth is a very marginal position in the philosophical debate about truth, but it is conceivable that there are more primitivists outside that debate. This would make perfect sense, as for a primitivist, there really is no incentive to debate truth. Truth, being a primitive, is not something that can be the topic of a genuine debate. For a historical overview and defense of primitivism, see Asay (2013).
} 
20th century, but most of those are coherence theories of knowledge or justification and the few that are about truth never played an important role in the debate (and moreover, most are not idealist), and contemporary variants of idealism such as antirealism (the idealism that doesn't dare to call itself such) do generally not come with a coherence theory of truth, but with a form of verificationism. Pragmatism, on the other hand, still exists, but contemporary pragmatists mostly side with deflationism. In other words, the field has been thoroughly shaken up. Moreover, many new theories and offshoots of correspondentism (such as truthmaker theory and the identity theory) have appeared, making it near impossible to sketch the current state of the field in just a view short paragraphs. (But I will try nevertheless, focusing on what matters for the main parts of this paper.)

\subsection{TRUTH PROPERTIES AND ONTOLOGICAL COMMITMENTS}

The main (but not only) point of contention between theories of truth is the nature and status of the truth property (/-ies) and associated truth predicate(s). (A predicate is a truth predicate if it is a linguistic representation or symbol of/for a truth property.) The most common answer to the question 'What kind of property is truth?' is that it is a substantive property. Truth-according to inflationism/substantivism - is theoretical-definable; that is, there is or can be a theoretical definition of 'true'. In this respect, 'true' is like 'fungus', for example: its theoretical definition captures what the members of a certain subclass within its domain have in common. Fungi have specific genetic, biochemical, and so forth properties, and for an organism, to have these properties means to be a fungus. Similarly, true sentences or propositions have something in common that determines that they are true. For correspondentism and related theories, that something is a truthmaker: what all true sentences or propositions (truthbearers) have in common is that they are made true by (their) truthmakers. What defines correspondentism is the truthmaking relation and the ontological commitment to (a specific kind of) individual truthmakers. ${ }^{6}$

Deflationists, on the other hand, deny that truth is a substantive property. True sentences or propositions have nothing in common (in addition to the truth property and an infinite array of disjunctive properties with truth as one of the disjuncts). All that can be said about truth, is what is said in Tarski's famous T-schema:

(Ts) " $p$ " is true $\leftrightarrow p$,

in which "..." stands for a name-forming device such as quotation marks in case of sentences or a phrase like 'the proposition that ...' in case of propositions. For

\footnotetext{
6 There are few philosophical concepts as obscure as that of 'truthmaking', but oddly, while among analytic philosophers it is bon ton to accuse non-Western and/or continental philosophy of conceptual obscurity, most of us seem to be blind for this log in our own eye. That said, Schnieder (2006) does an excellent job at making the concept less obscure, although I cannot shake off the suspicion that he does not so much clarify the concept of truthmaking (if there is one), but stipulates a particular version; a version, moreover, that is too thin to do all the work it is generally supposed to do.
} 
deflationists truth is a merely logical or syntactic property, or not a "real" property at all, but it has been pointed out by many that this would imply that truth cannot play any explanatory role either. ${ }^{7}$ For example, it would be impossible to explain meaning in terms of truth (or to base meaning on truth), which implies that deflationism precludes truth-conditional semantics. It is partly for this reason that Davidson opted for a third answer to the question what kind of property truth is: truth is a primitive (i.e. it is explanatorily basic). Like deflationists (and almost all other theorists of truth), Davidson accepts (Ts), but while for the deflationist (Ts) reveals something about truth, for Davidson (Ts) reveals something about meaning (of " $p$ "). Effectively, primitivism does not allow truth to be defined like deflationism, but does allow it an explanatory role (as in explaining meaning) like inflationism. There are no properties true sentences or propositions have that make them true, but there may be properties that true sentences or propositions have because they are true. Table 1 summarizes the key differences between the above three answers.

Table 1: three kinds of truth property

\begin{tabular}{l|l|l|l} 
Truth is a ... & $\begin{array}{l}\text { Can truth be } \\
\text { defined } ?^{8}\end{array}$ & $\begin{array}{l}\text { Can truth have an } \\
\text { explanatory role? }\end{array}$ & -ism \\
\hline substantive property & Yes. & Yes. & inflationism/substantivism \\
\hline primitive/basic prop. & No. & Yes. & primitivism \\
\hline logical/syntactic prop. & No. & No. & deflationism \\
\hline
\end{tabular}

A fourth answer to the question about the nature of the truth property (/-ies) is that truth is a functional property, which means that a truth predicate is identified (as such) by the functions or roles or functional roles it plays. Contrary to the previous three answers, which are mutually exclusive, functionalism can be combined with variants of the other answers.

There are two further questions about the truth property (/-ies) to which different theories give different answers. Firstly: What kind of things ("truthbearers") is truth a property of? (Or what kind of things is the predicate 'true' attached to?) Most common answers to this question are sentences, propositions, or beliefs. Avoiding a choice between those, I will use the term 'statement' in the rest of this paper as a neutral term. And secondly: How many truth properties are there? Usually this last question is understood as asking for the number of substantive properties. The answers then would be "zero" for deflationism and primitivism, "one" for correspondentism and most other inflationist theories, and "more than one" for

\footnotetext{
7 See, for example, Field (1986); Davidson (2005b); Horwich (1998).

8 "Defined" refers here to theoretical definition (similar to 'fungus' above); it does not mean lexical definition (capturing actual word use reflecting pre-theoretical understanding).
} 
pluralism. By implication, pluralism is inflationist. It is possible, however, that counting substantive and non-substantive properties separately results in more finegrained distinctions and/or suggest possibilities that have not been (thoroughly) explored yet. One such possibility, "quasi-pluralism", is suggested in section 3 of this paper.

Tarski's T-schema is not just accepted by deflationists and primitivists, but by almost all theorists of truth. Theories differ, however, in their interpretations of (Ts) (as illustrated by the difference between deflationism and Davidsonian primitivism). (Ts) means that "snow is white" is true if and only if snow is white. Hence, it seems to relate the truth of the statement to reality or some part or property thereof: true sentences somehow "correspond" to the world, but this is a loose sense of correspondence that is accepted even by primitivism. What defines correspondentism is a much stronger correspondence relation in which truthbearers are made true individually by discrete and individual truthmakers, most often facts. The nature of this claim and its implications can be made more precise by considering (Tf):

(Tf) " $p$ " is true $\leftrightarrow$ there exists some fact (that) $p$

(Ts) is often read as (Tf), or it is supposed that (Tf) follows from (Ts). It should be noted that (Tf) is as ambiguous as (Ts), and-depending on interpretation-is acceptable to most theorists of truth as well. This is because (Tf) does not specify the nature of the biconditional. A deflationist could read it as a merely conceptual relation: 'true' means the same as 'it is a fact that'. Alternatively, it could be read as implying an ontological dependency. For the correspondentist, true statements are ontologically dependent on facts (or other kind of truthmakers); a primitivist could opt for the converse (or side with the deflationist). That is, for the correspondentist, facts make statements true, while for such a primitivist true statements "create" corresponding facts as fact (i.e. they assign 'fact' status to some parts or aspects of reality). In other words, if ontological dependence is assumed, then either facts are truthmakers, or truths are factmakers. Correspondentism opts for the former, and is, therefore, committed to the existence of individual, discrete, ontologically independent ${ }^{9}$ facts (or other kind of truthmakers).

Theories accepting a looser sense of correspondence, on the other hand, imply no such ontological commitment. The distinction matters as it implies that correspondentism can only be attributed to a philosopher if she is ontologically committed to such truthmakers (and of course, to the truthmaking relation). There is no evidence in Lun-Heng 論衡, Wang Chong's major work, of such ontological commitment, but the metaphysical realism implicit in much of his critical writings implies correspondence in the loose sense. Wang Chong was, therefore, most likely not a correspondentist, ${ }^{10}$ but that does not imply that he implicitly adhered to one of

\footnotetext{
9 Or independent from true statements at least; they may be dependent on some other more fundamental kind of entity, as long as this doesn't lead to (vicious) circularity.

${ }^{10}$ Of course, absence of evidence does not imply evidence of absence. See also section 2.3.
} 
correspondentism's current contenders. The contemporary field of theories of truth does not necessarily exhaust the options. More likely it does not.

\subsection{PLURALISM ABOUT TRUTH}

Alethic pluralism or pluralism about truth is one of the most recent contributions to the debate. Pluralists such as Crispin Wright and Michael Lynch claim that there are multiple substantive and substantively different, domain-specific truth properties. For example, a version of pluralism could combine a coherentist notion of truth in one domain with a correspondentist notion in another. All such theories conform (or can be reduced) to a variant of the following schema:

(TP) $\forall p[\mathrm{~T}(p) \leftrightarrow \exists \mathrm{A}[\mathrm{A}(p) \wedge \Phi(\mathrm{A})]]$,

in which $\mathrm{T}$ is a general, domain-transcending, neutral truth predicate, A represents a domain-specific truth property, and $\Phi$ is the method of identification of $\mathrm{A}$ as a truth predicate (i.e. as representing a truth property). ${ }^{11}$ It should be noted, however, that (TP) does not specify conceptual priority, nor mentions domains. The latter is easily remedied:

$$
\left(\mathrm{TP}^{*}\right) \forall p[\exists \mathrm{D}[p \in \mathrm{D} \wedge(\mathrm{T}(p) \leftrightarrow \exists \mathrm{A}[\mathrm{A}(p) \wedge \Phi(\mathrm{A}, \mathrm{D})])]]
$$

in which D stands for the domain of $p$ and $\Phi$ becomes a two-place predicate to denote that it picks out a truth predicate $\mathrm{A}$ in a specific domain $\mathrm{D}$. (TP*) adds more complexity than necessary in the present context, however.

With regards to conceptual priority, several combinations of prior and posterior concepts are (in principle) possible. Most varieties of alethic pluralism assume conceptual priority of $\mathrm{A}$ and $\Phi$. T is then a generalized truth predicate and $\Phi$ - as in the above description - the criterion of identification of some A as representing a truth property. The reverse is also possible: $\mathrm{T}$ and $\Phi$ could be prior, and $\mathrm{A}$ the dependent or derivative. $\Phi$ then doesn't identify, but generate A-truth properties, and these A-truth properties are (more or less) elaborations or applications of (relatively) basic T-truth. Bo Mou (2009) seems to argue for something like this. ${ }^{12}$ A third

${ }^{11}$ See Lynch (2013), p. 26 for a version of this schema that, aside from partially specifying $\Phi$, differs only notationally.

12 There is reason to doubt that Mou's "substantive perspectivism" is a variety of alethic pluralism. According to Mou, A-truth properties are "substantive", but his section 6.2.1 shows that they are not theoretical-definable, which I take to be the defining criterion of substantiveness (see section 1.1). Mou's A-truth properties can play explanatory roles and are metaphysically and semantically relevant, which means that they are primitive/basic (see table 1). Effectively, Mou reduces the differences between kinds of truth properties to a single dimension (their explanatory role), thus conflating primitive properties with substantive properties. However, alethic pluralism needs substantive A-truth properties (in the sense of 'substantive' employed here) to substantiate its core notion of differing Atruth properties (see sections 2.3 and 3), and lacking such substantive A-truth properties, Mou's theory 
possibility may be that $\mathrm{T}, \mathrm{A}$, and $\Phi$ all come together (i.e. none is prior or posterior), in which case $\Phi$ specifies a conceptual relation between general T-truth and the specific A-truths.

The various differences between versions of pluralism can be best understood in terms of their answers to three questions about (TP): (i) Which predicates/properties $(\mathrm{T}, \mathrm{A}, \Phi)$ are prior, and which are derived? (ii) What is the nature of $\Phi$ ? And: (iii) Is T-truth a substantive property? ${ }^{13}$ Because the dominant pluralisms (i.e. those defended by Wright and Lynch) all give the same answer to (i) - that is, A and $\Phi$ are prior, $\mathrm{T}$ is a generalization-I will further ignore that question here. (Lacking a neutral term for $\Phi$, I will, for the same reason, refer to $\Phi$ as 'identification' in the following, but it should be taken into account that other conceptual priorities are (at least in principle) possible.)

The simplest form of pluralism is disjunctivism, which can be formally characterized as:

$$
\text { (Disj) } \forall p\left[\mathrm{~T}(p) \leftrightarrow\left(\left(p \in \mathrm{D}_{1} \wedge \mathrm{A}_{1}(p)\right) \vee\left(p \in \mathrm{D}_{2} \wedge \mathrm{A}_{2}(p)\right) \vee \ldots \vee\left(p \in \mathrm{D}_{\mathrm{n}} \wedge \mathrm{A}_{\mathrm{n}}(p)\right)\right)\right]
$$

in which $D_{1} \ldots D_{n}$ represent domains and the $A_{i}$ predicates represent domain-specific truth properties. Hence, a statement in domain 1 is $\mathrm{T}$-true if it is $\mathrm{A}_{1}$-true, and so forth. For disjunctivism, $\Phi$ is, therefore, something like "being the truth property/predicate listed as the one applying in the domain of $p "$. T-truth is not a substantive property. The various $\mathrm{A}_{i}$ properties are substantive properties, but $\mathrm{T}$-truth is nothing but the disjunction of all those $A_{i}$ properties. Wright's (2001) version of pluralism gives a similar answer to the third question, but a more sophisticated one to the second: $\Phi$ is a collection of "platitudes" that serve to identify a truth property/predicate. This collection of platitudes has more central and more peripheral members; one of the most central platitudes is (Ts) or a variant thereof.

Lynch defended different versions of pluralism before and after 2006. (See Lynch 2013 for summaries of his earlier and later positions and for references.) Before, he identified truth with the role property; that is, with "the property of having a property that plays the truth-role" $(2013,29)$, which is the whole part right of the biconditional in (TP), implying that the conditional in (TP) is a conceptual relation. $\Phi$ then, is "playing the truth-role". More recently, he speaks of $\Phi$ as "having the truish features essentially" (p. 31). Those "truish features" are platitudes or truisms similar (but not identical) to Wright's. The subtle differences between Wright's and Lynch's $\Phi$ matter, but the (here) most important difference is between their answers to the third question: for Lynch (after 2006), T-truth is a substantive property; that is, it has a theoretical definition and explanatory power aside from or in addition to the various

of truth is closer to the "quasi-pluralism" I am suggesting in section 3 than to the pluralism of Wright and Lynch.

${ }^{13}$ There are other differences, but beyond the rhetoric, all (here) essential differences boil down to the answers to these questions. 
$\mathrm{A}_{\mathrm{i}}$ properties. This gives Lynch an advantage over Wright and disjunctivism in dealing with the problem of mixed discourse. To illustrate this problem, consider the following two propositions:

(1) Whipping is painful and whipping is bad.

(2) Whipping is cruel.

(1) is a compound proposition and (2) is a simple proposition, but both are examples of mixed discourse. In (1), the first conjunct belongs to a non-normative domain, while the second belongs to a normative domain. 'Cruel' in (2) is an example of a thick ethical concept that crosses domain boundaries: it is more or less in two domains at once.

If the two conjuncts in (1) are abbreviated as $a$ and $b$, respectively, then from the nature of conjunction as a truth-functional connective it follows that $\mathrm{T}(a \wedge b)$ iff $\mathrm{T}(a)$ and $\mathrm{T}(b)$, and if $\mathrm{A}_{1}$ and $\mathrm{A}_{2}$ are the domain-specific truth properties for the relevant non-normative and normative domains, then from (TP) follows that $\mathrm{T}(a)$ iff $\mathrm{A}_{1}(a)$ and $\mathrm{T}(b)$ iff $\mathrm{A}_{2}(b)$. If, however, only A properties are substantive, and $\mathrm{T}$ is not a "real" property or a merely logical/syntactic property, then saying that (1) is true is not really saying anything about (1) at all, but just about its parts. $\ulcorner\mathrm{T}(a \wedge b)\urcorner$ then, is nothing but convenient shorthand for $\left\ulcorner\mathrm{A}_{1}(a) \wedge \mathrm{A}_{2}(b)\right\urcorner$. If, on the other hand, $\mathrm{T}$ is a substantive property (in addition to the substantive A properties), then $\ulcorner\mathrm{T}(a \wedge b)\urcorner$ means and/or implies something more than just $\left\ulcorner\mathrm{A}_{1}(a) \wedge \mathrm{A}_{2}(b)\right\urcorner$ (leaving aside what exactly that "something" is). ${ }^{14}$

This doesn't solve the problem presented by (2), however. Unlike in the case of mixed conjunctions like (1), there is only one proposition here: one proposition that seems to be both normative and non-normative at the same time. One could, of course, suggest that (2) can be reduced to (1), but that suggestion is controversial among moral theorists. Another option could be that propositions that are in multiple domains need to be A-true in all those domains to be T-true. I will not discuss this suggestion here, but concentrate on McLeod's reading of Wang Chong as a pluralist instead.

\section{WAS WANG CHONG A PLURALIST?}

There are three pairs of contrasting concepts related to truth (and falsity) that occur in Lun-Heng: shi/fei 是非, ran/fou 然否, and SHI/xu 實虛. To avoid excessive use of Chinese characters, I will write SHI 實 in small capitals to distinguish it from (lowercase) shi 是. McLeod's (2011) reading of Wang Chong as a pluralist identifies shi and ran as A predicates (in moral and non-moral domains, respectively), and SHI

${ }^{14}$ The foregoing heavily depends on the conceptual priority assumed in most pluralisms (i.e. $\mathrm{T}$ as a generalization). Indeed, he problem of mixed discourse only arises under that assumption. If on the other hand, $\mathrm{T}$ is the prior concept and A-truths are applications or variants thereof, then the problem does not arise. 
as either $\mathrm{T}$ or $\Phi$ or both (this is somewhat ambiguous). The domain boundary between the moral and non-moral domains coincides with the shi/ran distinction: "Non-moral statements cannot be 是 shi, just as moral principles cannot be 然 ran" (54). McLeod writes that SHI "can be thought of as expressing a second-order property - the property of having a property or properties that we should and do seek when appraising statements" (55), ${ }^{15}$ and envisages this theory as a solution to the problem of mixed conjunctions. In the latter context it becomes clear that $S H I$ is $\mathrm{T}$, and that $\Phi$ is: to be "a property that we should and do seek when appraising statements ". 16

McLeod further suggests that his pluralist reading of Wang Chong is closer to Wright than to Lynch and because of its supposed solution to the problem of mixed conjunctions can help in the contemporary debate about truth and pluralism. It seems to me that his theory is rather similar to Lynch's, however, and very different from Wright's (particularly, it shares the substantivity of $\mathrm{T}$ and the suggestion that this solves the problem of mixed conjunctions with Lynch), ${ }^{17}$ but that is not an important issue (although this observation does raise the question whether the theory does actually add anything new to the debate). More important is that there is reason to doubt that it can be a contribution to the contemporary debate. In reference to $\Phi$ as the "property that we should and do seek when appraising statements", McLeod writes that this is "a brute fact about humans", that "Wang Chong takes this normativity as explanatorily basic" and that "this certainly would strike most of us in the contemporary Western-based philosophical tradition as strange or implausible" (56). However, if the latter is the case, then a theory of pluralism built on such a "strange and implausible" foundation cannot possibly be a contribution to the contemporary debate. (That would be like asking analytic metaphysicians to consider a theory founded on an explanatorily basic notion of $q i$ 氣.)

Furthermore, there are reasons to doubt McLeod's attribution of pluralism as well. The attribution would require (among others) that (1) SHI, shi, and ran are truth predicates, (2) that they stand for substantive properties, and (3) that there is a clear domain distinction between shi and ran and that shi and ran are substantively different. All of these claims are problematic, however, as I will show below.

15 Strictly speaking this way of phrasing is incorrect. A second-order property is a property of a property (or a kind of properties, but that is only notationally different). The property of having a property is not a second-order property, but it may involve one if this implies an appeal to a kind of properties. In (TP), $\exists \mathrm{F}[\mathrm{F}(p) \wedge \Phi(\mathrm{F})]$ formalizes the property of having a property; therein, $\Phi$ is a second-order property, but $\exists \mathrm{F}[\mathrm{F}(p) \wedge \Phi(\mathrm{F})]$ as a whole is a complex first-order property of $p$.

16 The phrase "the property of having a property or properties that we should and do seek when appraising statements" describes the right hand side of (TP) as a whole. $\Phi$ is just part thereof.

17 McLeod writes that a mixed conjunction is $S H I$ "just in case it has the properties we do and should seek when appraising sentences" (56). That is the substantive nature of T-truth (i.e. SHI). 


\subsection{THE (A)SYMMETRY OF SHI/XU}

Of the three pairs of truth-like concepts, shi/fei 是非, ran/fou 然否, and SHI/xu 實虛, the first two are obviously symmetrical, but this is not the case for the third. That is, shi and fei are contradictories and therefore symmetrical, and so are ran and fou, but the logical relation between $S H I$ and $x u$ is less clear. The problem is that-given the meaning of $x u$ as something like 'mere attractive appearance' (see section 3.2 of McLeod's paper) - there are two possibilities, symmetry and asymmetry, but both lead to the conclusion that SHI is not general T-truth in (TP) or even not a truth predicate at all (i.e. does not represent a truth property).

McLeod argues explicitly for symmetry in his section 3.2. This means that if $x u$ is mere attractive appearance, then SHI, "as the opposite of $x u$ " (50), is non-mereappearance-i.e. objectively true/real-but also non-attractive (at least to "ordinary people"). He bases this view on a single passage in Dui-Zuo 對作 $\S 2^{18}$ in which Wang Chong claims that “SHI is not quickly/easily understood” (實事不能快意). The passage does not imply (or even suggest) that such difficulty or unattractiveness is a defining characteristic of SHI, however - it may be mere accidental property. Furthermore, if McLeod is right that $S H I$ and $x u$ are contradictories like the other two pairs, then this would lead to another asymmetry, namely between $S H I / x u$ and the other two pairs, which do not (directly) concern attractiveness, and that would seem to disqualify $S H I$ as a $\mathrm{T}$ generalization of shi and ran. What is more, 'unattractively true' does not represent a truth property at all (but a compound property also involving truth) and certainly not one that would be picked out by McLeod's $\Phi$.

Symmetry then, is not an option, but neither is asymmetry. If $S H I$ is a genuine truth predicate, and $S H I$ and $x u$ are thus not contradictories, then $x u$ implies not-SHI, but not the other way around: there are (then) multiple ways of being not-SHI (false). Although I think that this is a much more plausible interpretation of $S H I / x u$, it does, however, create a new problem illustrated by figure 1 .

Figure 1: logical relations between five of the six concepts

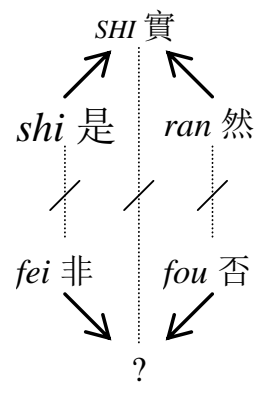

18 The paragraph number refers to the Chinese Text Project edition at http://ctext.org/Lun-Heng 
The figure shows the logical relations between five of the six concepts, omitting $x u$, and assuming McLeod's pluralist interpretation. The arrows stand for conditionals: anything that is shi is also SHI, or formally: $\forall p[\operatorname{shi}(p) \rightarrow \operatorname{SHI}(p)]$, and so forth. The crossed-out dotted lines stand for contradiction: $\forall p \neg[\operatorname{shi}(p) \leftrightarrow f e i(p)]$, and so forth. What is conspicuously missing in the figure is the contradictory of SHI. If shi and ran are two different ways of being $S H I$, and $S H I$ is, therefore, general T-truth in (TP), then fei and fou as, respectively, not-shi and not-ran must be two different ways of being not-SHI. $\mathrm{Xu}$ is not not-SHI ( $\mathrm{xu}$ implies not-SHI, but not conversely), but neither is there another (obvious) candidate for not-SHI in Lun-Heng (aside, perhaps, from 不實, although this does not seem to occur as an explicitly general/neutral form of $f e i$ and $f o u)$. But this means that from $f e i(p)$ we can infer $\neg \operatorname{shi}(p)$, but from $\neg \operatorname{shi}(p)$ we cannot infer $\neg \operatorname{SHI}(p)$ (that would be the fallacy of denying the antecedent). In other words, if there is no contradictory of $S H I$, then one cannot derive not-SHI from fei or fou either, but that is absurd and cannot charitably be attributed to Wang Chong. Of course, this conclusion does not follow if we add two additional assumptions:

(3) $\forall p[\operatorname{SHI}(p) \rightarrow(\operatorname{shi}(p) \vee \operatorname{ran}(p))]$

(4) $\forall p[(f e i(p) \rightarrow \neg \operatorname{ran}(p)) \wedge($ fou $(p) \rightarrow \neg s h i(p))]$

(i.e. that there are two and only two ways of being SHI, namely shi and ran; and that fei, respectively fou, implies not-ran, respectively not-shi). ${ }^{19}$ It may very well be the case that Wang Chong held both, at least implicitly, but especially (3) would require textual support as this assumption is not obvious. Furthermore, it is rather implausible that Wang Chong would assume all these logical relations (those in (3) and (4) and those mentioned above) and not assume or introduce a contradictory of SHI (which would allow much easier and more intuitive inference of not-SHI from fei). The fact that he did not, suggests that he didn't feel the need to do so, which in turn suggests that SHI plays a different role than that of general T-truth.

To phrase the problem in somewhat different (and much weaker) terms: In a genuine pluralism, one would expect a general(ized), domain-transcending concept to behave in ways similar to its domain-specific counterparts. If domain-specific concepts come in contradictory pairs, then one would expect the general(ized) concept to do the same. If the apparent general(ized) concept behaves differently (in this respect) than the domain-specific concepts, then most likely it is not a general form thereof (but it may be related in another way, of course), and one is probably not dealing with a genuine pluralism. But if this is right, then $S H I$ is not a truth predicate, or at least not general T-truth in (TP).

19 There are other sets of additional assumptions possible that would lead to the same results, but those would be considerably less intuitive, and therefore less plausible, than these. Notice also that (4) depends on (3), and that if (3) would distinguish more truth properties, (4) would need to be adapted to that. With these assumptions, from $f e i(p)$ and (4) follows $\neg \operatorname{ran}(p)$, and from $\neg \operatorname{ran}(p)$ and $\neg \operatorname{shi}(p)$ and (3) follows $\neg \operatorname{SHI}(p)$ by modus tollens. 


\subsection{THE IDENTIFICATION OF TRUTH PREDICATES}

The problem addressed in the previous sub-section raises a more general question: To what extent is McLeod's case for pluralism dependent on and/or motivated by translation or interpretation of the apparently truth-like concepts (shi, ran, SHI) as truth predicates?

To assess the implications of this question, consider the following imaginary case: On some small island there are red and green fruits and feathered and featherless nonsea animals. The language of the Islanders, Islandish, makes these distinctions and further includes (among others) the predicates 'edible' and 'poisonous'. Red fruits and feathered (non-sea) animals are considered edible by the Islanders. Thus far, the case is exactly parallel to the above: red is $s h i$, green is $f e i$, feathered is ran, featherless is fou, edible is SHI and poisonous is $x u$. Obviously, no one would want to say that the Islanders have a pluralistic notion of edibility, so there must be some significant difference between this case and the case of shi/ran/SHI. Assume further that the tribe on the neighboring island speaks a different language-let's call it Neighborese - and that Neighborese uses one and the same predicate term for edible stuff, red fruits, and feathered animals. Now, what reason do we have to believe that English does not relate to Wang Chong's (use of) Chinese, in the same way that Neighborese relates to Islandish? The problem is that without an answer to this question, the thesis that Wang Chong's notion of truth is pluralistic while the Islanders' notion of edibility is not, is incongruent and therefore indefensible. There are significant differences between the two cases, however, and some of these undermine the analogy, but those that do so, reveal problems that undermine McLeod's attribution of pluralism even more.

The most obvious difference is that 'edible', 'red', and 'feathered' have very different meanings, while shi, ran, and SHI have very similar meanings. However, these conceptual (dis)similarities are (dis)similarities to us; a speaker of Neighborese may perceive very different conceptual (dis)similarities. Moreover, relying on this difference between the two cases would be begging the question as the (relevant) conceptual similarity between shi, ran, and $S H I$ is part of what needs to be established to attribute pluralism. ${ }^{20}$

A second difference is that the above suggests that Neighborese can only translate all three terms with one and the same term, but there is no similar necessity in English

\footnotetext{
${ }^{20}$ Perhaps, it would not be seriously question-begging to rely on some kind of minimal similarity, such as a similarity in functional role, but it is entirely possible that 'edible', 'red', and 'feathered' function very similarly in Islandish - we cannot tell without knowing more about the language. More important, however, is that "similarity in functional role" means that the three predicates conform to one and the same rule, and and as Kripke/Wittgenstein pointed out, anything can be made to accord with some rule (or, there is always a rule that actual use accords to). In other words, shi, ran, and SHI may be functionally similar, for example, in the sense that they are all disquotational in the sense implied in (Ts) - assuming that they are - but there is some rule under which 'edible', 'red', and 'feathered' are functionally similar as well.
} 
to translate shi, ran, and SHI the same. Shi could be translated with 'right', for example, and ran with 'is the case' (as suggested by McLeod on p. 46). Considering that $S H I$ 實 is used in many different senses including 'reality' and 'actuality' (see section 2 of McLeod 2011), and given Wang Chong's use of the term in Lun-Heng, 'objectivity/objective' seems a plausible alternative to 'truth/true'. Moreover, 'objective' seems a more natural contrasting term to $x u$ as 'mere attractive appearance' than 'true'. While this difference may undermine the Islanders analogy, it undermines the attribution of pluralism to an even greater extent. The notions of objectivity and truth are closely related, but sufficiently different to not be considered the same (kind of) notion or to stand in the relation of general form $\mathrm{T}$ and domainspecific A in (TP), and therefore, do not suggest pluralism. And if the choice for a different, and not prima facie implausible translation removes the suggestion of pluralism, then there is not much of a case for pluralism to begin with.

There is a third difference between the two cases that becomes obvious when considering McLeod's main argument for the pluralist interpretation:

the ability to discriminate between 實 $s h i$ and 虛 $x u$ allows us to both distinguish between 然 ran and 否 fou and to distinguish between 是 shi and 非 fei. In order for this to be the case, there must be some univocal concept of 實 shi that captures the similarities between the various properties which count as shi-properties. (55)

The obvious disanalogy between McLeod's argument (and the passages from LunHeng it is based on) and the case of the Islanders and 'edibility' is the difference in discriminatory dependence. It seems plausible indeed that Wang Chong (at least in Duizuo) held that the ability to discriminate SHI from $x u$ allows discrimination of the other two contrasts - in that direction - while the dependency in the Islanders case is obviously the other way around (the discrimination of edibility is the dependent rather than the independent). Although this may very well be a refuting disanalogy, there is a serious problem with McLeod's argument. Discriminatory dependence does indeed imply some commonality, but it does not imply that that commonality must take the kind of form implied in pluralism - there are many other possibilities. For example, the ability to discriminate the letters $a$ and $u$ allows me to discriminate the word 'fan' from 'fun' and 'staff' from 'stuff'; the ability to discriminate between light and dark allows me to discriminate between day and night, and between white and black; and the ability to discriminate between earthquakes and storms allows me to discriminate between a tsunami and a storm surge. In none of these cases it follows that the concepts are relevantly similar and/or related in a relevant way (rather, in the first case the relation is one of parts and wholes, in the second there is (a.o.) a phenomenological similarity, and in the third there is a causal relation). A relation between discriminatory abilities implies a relation between some characteristics, but not necessarily between relevant characteristics, and not necessarily a relevant kind of relation.

Furthermore, as an argument for pluralism the discriminatory dependence argument relies heavily on a presumed (and thus question-begging) similarity 
between the concepts involved, which is illustrated by inserting the alternative translations suggested above into the quote by McLeod:

The ability to discriminate between what is objective and what is mere attractive appearance allows us to both distinguish between what is the case and what isn't and to distinguish between right and wrong.

Phrased like this, there doesn't seem to be much of an argument for pluralism.

\subsection{ARE SHI AND RAN SUBSTANTIVE PROPERTIES?}

As mentioned above, contemporary pluralism about truth is inflationary. That is, it assumes that there are multiple substantive, and substantively different truth properties. The reason for this assumption is that it would be difficult otherwise to meaningfully connect and distinguish the various truth properties. For example, if a pluralism distinguishes true- 1 and true- 2 and these are not substantive properties, then statements that are true- 1 have nothing in common with each other except that they are true-1, and nothing in common with statements that are true- 2 at all. Hence, there would be no connection whatsoever between true-1 and true-2; no reason to assume that they are similar notions (i.e. that they are both truth properties), and thus no pluralism. If another pluralism would distinguish true- 3 and true- 4 , but both would stand for truth as correspondence, then there would be no substantive difference between them, and therefore, no reason to distinguish them and no pluralism. The latter case would be a kind of quasi-pluralism at best; that is, a difference in predicate terms and domains only, comparable to the distinction between iru and aru in Japanese for 'being' of animates and inanimates, respectively. (A deflationist or primitivist might try to escape the conclusion that true-1 and true-2 have nothing in common by bringing in functionalism. 'True-1' and 'true-2' are then identified as truth predicates by the functional roles they play. This would, however, preclude any substantive difference between the truth properties, leading to the quasi-pluralism of the second scenario.) Consequently, a pluralist interpretation of Wang Chong requires that shi and ran represent substantive, and substantively different properties (i.e. that the difference between them amounts to more than just a difference of domains as in iru/aru). The problem is that there doesn't seem to be sufficient evidence for either of these requirements.

There is nothing in Lun-Heng that suggests that Wang Chong considered truth to be a substantive property. It was already mentioned in section 1.1 that the correspondence theory cannot be plausibly attributed to Wang Chong, but there are other options for a substantive truth property, such as verificationism and coherentism. There are a few occasions where he suggests a relation between evidence and truth, which might suggest something like verificationism, but a close reading teaches that the relation is indirect: evidence establishes truth. ${ }^{21}$ In more

${ }^{21}$ See for example, Yu-Zeng 語增 §11, Zhi-Shi 知實 §1, and Shi-Ying 是應 §22. 
modern terms, what Wang Chong argues (or assumes) in those passages is that justification depends on evidence, not that truth (itself) depends on evidence or that evidence makes statements true.

The closest Wang Chong comes to coherentism is his argument in Lei-Xu 雷虛 $\$ 20$ (see the second quote below) that two contradictory statements cannot both be right. A coherentist notion of truth, however, asserts that coherence makes statements true, which is a much stronger claim than Wang Chong's. The passage only claims that incoherence implies non-truth, and from that it cannot be inferred that coherence implies truth (or even makes true). A more plausible interpretation is that coherence is a necessary but not sufficient condition for justification. (Combining this with the above: justification requires both evidence and coherence.)

Absence of evidence (for substantive truth properties) does not imply evidence of absence, of course, but given the importance of truth to Wang Chong - telling the truth and dispelling falsehoods is the whole point of his book - it would be odd (to say the least) if he adhered to a substantive notion of truth without ever suggesting what true statements have in common. The fact that he-in a book in which truth plays such a central role - never even hinted at what truth is or what shi, ran, or SHI mean strongly suggests that he (implicitly!) considered truth to be primitive. (This still leaves many options open: shi and ran could be primitives and $S H I$ defined as shi or ran; or $S H I$ could be primitive and shi and ran defined as domain-specific versions thereof; or all three could be primitive; and so forth.)

Furthermore, there isn't much evidence for substantial difference between shi and ran either, and even the domain distinction seems to be rather fluid. One might expect ran to be more explicitly connected with evidence and facts than shi, for example, but this turns out not to be the case, as illustrated by the following fragment, which also raises the question of translation again:

考察前後, 效驗自列, 自列, 則是非之實有所定矣。If we examine what comes first and [what comes] later, then the evidence arranges itself, and if [the evidence] arranges itself, the SHI of shi/fei is determined! (Yu-Zeng 語增 §11)

I have left 是非之實 more or less untranslated here. If SHI is translated as 'objectivity/objective' as suggested above and shi and $f e i$ as 'right' and 'wrong' respectively, then 是非之實 would be "the objectivity of right and wrong". The phrase 是非之實 also occurs in Lei-Xu $§ 20$ in the context of a discussion of two contradictory views on the nature of thunder:

二家相違也, 并而是之, 無是非之分。無是非之分, 故無是非之實。 The two houses are in mutual opposition, but if both would be shi, then there would be no distinction between shi and fei. And if there would be no distinction between shi and fei, then there would be no $S H I$ of shi/fei.

In both these fragments shi/fei is applied to non-moral, rather than moral domains (history in the first, thunder in the second). That is, shi/fei occurs where the pluralist 
interpretation predicts ran/fou. It seems to be the case that shi/fei can be substituted for $\mathrm{ran} / \mathrm{fou}$ (but not the other way around, and perhaps only in certain circumstances), except in cases where it is necessary to make an explicit shi/ran distinction. That would be impossible, however, in case of the strict domain-dependency implied in pluralism. In other words, if shi is not domain-specific, then it cannot be a truth predicate in the A role in (TP).

On the other hand, the domain boundary does not need to coincide with the terminological boundary (between shi and ran). This isn't the case in English either, where only the use of adjectives would distinguish different truth properties. It is plausible that there are two truth properties in Lun-Heng indeed, one of which can be expressed by both shi and ran, and one of which can be expressed by shi only. This would make sense if the former is something like non-moral or non-normative truth and the second moral or normative truth, and if ran is understood as a loose correspondence notion (see section 1.1). (McLeod's case for the domain distinction in Lun-Heng is strong, and is supported by much more textual evidence than he quotes.) Rather than translating shi and ran as 'right' and 'true', better translations would then be 'truth/true/right' (depending on context) for shi, and 'is the case' (or something similar) for ran. (This would change the translation of 是非之實 into “the objectivity of truth and falsehood", which appears to be exactly what Wang Chong meant with the phrase in the above two quotes.) It should be noted, however, that this is not the shi/ran pluralism McLeod is suggesting.

\section{QUASI-PLURALISM}

The previous sections present a number of arguments against McLeod's interpretation of Wang Chong as a pluralist: (1) the problematic (a)symmetry of SHI/xu, suggesting that SHI is not a general(ized) truth predicate T; (2) the dependency on a particular translation or interpretation of the apparent truth-like concepts involved; (3) the lack of evidence for substantivity of shi and ran; and (4) the lack of a sharp and clear domain boundary between shi and ran. Although this seems more than sufficient to discard McLeod's attribution of pluralism to Wang Chong, I find the idea too valuable (and the underlying domain distinction too pervasive) for such blanket rejection. For that reason, in this last section I want to explore the question whether the critical remarks in the previous sections leave any room for some kind of pluralism.

There is little evidence that Wang Chong thought of the normative domain as comprising more than ethics, but I will adopt a more general notion of the normative domain here (distinguishing sub-domains when necessary). In Wang Chong's terms (or what I take them to be), non-normative truth can be expressed with shi and ran, but truth in the normative domain only with shi. I do not consider Wang Chong's third truth-like notion, SHI, to be a truth predicate for reasons explained in section 2.1, but to mean something like 'objective/objectivity', and because of this, it plays no

role in the following. (That is not to say that the concept is not important, or that it is unrelated to truth, just that it isn't 'truth'.) Rather, shi can also function as general T- 
truth in (TP), in the same way that 'true' can be used in any domain and as general(ized) truth predicate in English, marking distinctions when necessary by means of adjectives. (The following is not dependent on Wang Chong's terminology, however, but merely takes inspiration from it.) What identifies truth properties/predicates (i.e. $\Phi)$ is Tarski's disquotational schema (Ts), and nothing but (Ts). (Note that while this $\Phi$ picks out shi and ran as truth predicates, it is far less clear whether $S H I$ is similarly disquotational.)

What appears to be the most serious problem for a pluralist interpretation of Wang Chong is that identified in section 2.3: the truth predicates involved do not seem to stand for substantive properties. A defensive response to this objection would be to deny the conclusion. As mentioned, absence of evidence does not imply evidence of evidence: perhaps, Wang Chong really held truth properties to be substantive and just did not realize the importance of substantiating (or even mentioning) their substantivity. This, for reasons mentioned, seems a rather weak response, however. The alternative is biting the bullet: assuming that the truth properties expressed by shi and ran are primitive indeed and seeing where this leads (if it leads anywhere). (To soften that bullet, see Asay 2013 for a rigorous defense of primitivism.)

The essential difference between the primitivist and the inflationist is that the former takes truth to be (explanatorily) basic: there are no more basic concepts that explain or define truth, and nothing "makes statements true" (except, perhaps, in the very loose sense that true statements are true because of how the world is). But at the same time, truth being basic means that other concepts and ideas can be built upon it: truth can (help) explain other concepts (such as meaning in Davidsonian primitivism), and truth can have implications. And if that is the case, then it would seem that different domain-specific truth properties can have different domain-specific implications. That, however, is not the case, or not exactly at least. If truth is basic and therefore undefinable and unexplainable in more basic terms, then we cannot make good sense of the idea of different notions of truth. We can only distinguish notions of truth if we can compare their definitions or compare what follows from them and cannot be attributed to other differences. The latter, however, is never the case: any apparent difference between implications of different truth properties can be explained by and attributed to a difference between domains.

It seems then, that primitivism and pluralism cannot be usefully combined, that any attempt to do so leads to the quasi-pluralism of the iru/aru distinction: plants and buildings aru (are), animals and people iru (are), but there is no substantive difference between those two verbs, nothing hangs on the difference. The difference between the domains is real enough, however; nothing may hang on the difference between iru and aru (except when used as auxiliary verbs), but the difference between animates and inanimates matters, at least in some contexts. Similarly, the difference between normative and non-normative domains matters, at least in some contexts. Perhaps, it is not truth itself that differs between domains, but that does not preclude other truth-related differences. If that is the case, the different truth terms merely mark those related differences. This raises the question, of course, what those 
truth-related differences between domains could be. To that question, I have two answers, one metaphysical and one epistemological, but both deserve a much more extensive treatment than is possible here, and there may be further answers.

The metaphysical difference concerns the primitivist reading of (Tf). If the biconditional in (Tf) is understood to imply ontological dependence, then a primitivist can only read ( $\mathrm{Tf}$ ) as "true statements are factmakers" (in contrast to the correspondentist reading of "facts are truthmakers"). Davidson, the most outspoken primitivist, never made this claim, but Samuel Wheeler (2014) argues convincingly that it does follow from Davidson's account of truth and interpretation. The metaphysics of "factmaking", however, differs somewhat between normative and non-normative domains: in the former the true statement creates the fact, while in the latter it merely assigns the status of 'fact' to a thereby delimited and described chunk or part of (objective/independent) reality. Non-normative factmaking creates facts $a s$ facts, but only as facts.

The epistemological difference is a difference in justification, a notion so close to truth, that the two are rarely kept apart sufficiently, and nowhere is this as clear as in the idea of truth as a goal of inquiry. "We do not aim at truth but at honest justification," wrote Davidson $(1999,461)$. His point was that when we say that we want our statements or beliefs to be true, what we want is overwhelming evidence or an irrefutable argument; hence, justification. And moreover, we cannot ask for more than that; "it makes no sense to ask for more" (id; see also 2005a, chapter 1). ${ }^{22}$ Davidson defended a coherence theory of justification (2001, ch. 10): a belief is justified (or one is justified to believe that a belief is true) if it coheres with most of one's other beliefs, especially with one's "most basic" beliefs, where those "most basic" beliefs provide the most direct link to reality, thus guaranteeing that "coherence yields correspondence" $(2001,137)$. Although he assumed that this is sufficient for justification in all domains (or more accurately, he did not distinguish domains), I think there are good reasons to believe that there are differences between normative and non-normative domains. What distinguishes justification in normative from non-normative domains is firstly the lack of (obvious) "most basic" (purely) normative beliefs (at least in the same sense of 'most basic'), secondly the asymmetry between the two domains in the sense that justification in the normative domain also requires coherence with the non-normative domain but not vice versa, ${ }^{23}$ and thirdly

22 The rejection of truth as a goal of inquiry seems to conflict with the importance truth plays in Davidson's philosophy as a whole. It very much seems the case that (for Davidson, as well as for many others) the pursuit of truth is the purpose of science and philosophy. However, if Davidson (and others who made a similar point) are right that truth cannot be a norm, then 'truth' in 'aiming for truth' can only be a (misleading) metaphor for justification (which illustrates and strengthens the point made above: truth and justification are not kept apart sufficiently). (Mou (2009) suggests another way to resolve the tension by distinguishing truth pursuit as a tactical goal and as a strategic goal. The former is what Davidson rejects; the latter is what he (implicitly) affirms. It is not entirely clear, however, (to me, at least) whether truth pursuit as a strategic goal can be made sufficiently precise without reducing it to tactical goals.)

${ }^{23}$ Except, of course, that coherence itself is a normative notion (belonging to the logical sub-domain). 
that normative domains have regulatory purposes (that is what 'normative' means). Arguably, the purpose of the normative sub-domain of logic is to regulate reasoning, and the purpose of the sub-domain of ethics is to regulate society (or to regulate behavior to make society possible). These regulatory purposes need to be taken into account: justification in those domains also requires coherence with those purposes.

These metaphysical and epistemological differences between the normative and non-normative domains illustrate that even if truth isn't a substantive property, there are differences between those domains that are closely related to truth. Hence, quasipluralism may not be a pluralism about truth, strictly speaking, but it is certainly a pluralism relevant to truth. ${ }^{24}$ Of course, it is implausible that Wang Chong held exactly this pluralism - it relies too much on Davidson for that suggestion to make sense. Nevertheless, it seems to me that Wang Chong implicitly held something very much like this. The essential difference is in the explicitness of the above versus the implicitness of Wang Chong's account of truth. It is the explicitness that allows a more detailed elaboration, and it is mainly in that elaboration (i.e. the specific domain differences suggested above) that the two quasi-pluralisms differ. Wang Chong's "theory" of truth probably remained implicit because there was no need to make it explicit (lacking a debate about the nature of truth), and theoretically underdeveloped because it remained implicit. It should be noted that the suggestion in this section remains underdeveloped as well, both as a theory about truth and as an interpretation of Wang Chong's (implicit) "theory" of truth. And although this interpretation differs significantly from McLeod's, it is based on his suggestion and agrees with him in at least one important respect: "the pluralist conception of truth arising from Wang's work differs significantly from contemporary pluralist theories of truth" (40). That is more than enough reason for further research, and to award Wang Chong a less peripheral position in philosophical attention space.

\section{REFERENCES}

Asay, Jamin (2013), The Primitivist Theory of Truth (Cambridge: Cambridge University Press).

Davidson, Donald (1999), "Reply to Pascal Engel”, L.E. Hahn (ed.) (1999), The philosophy of Donald Davidson (Chicago: Open Court), 460-461.

- (2001), Subjective, Intersubjective, Objective (Oxford: Oxford University Press).

- (2005a), Truth, Language, and History (Oxford: Oxford University Press).

- (2005b), Truth and Predication (Cambridge MA: Harvard University Press).

Field, Hartry (1986), "The Deflationary Conception of Truth", in G. MacDonald \& C. Wright (eds.), Fact, Science and Morality (Oxford: Blackwell), 55-117.

Horwich, Paul (1998), Truth, 2nd edition (Oxford: Blackwell).

\footnotetext{
${ }^{24}$ Because quasi-pluralism is not a pluralism about truth itself, it does not seem to have a problems with mixed discourse, but this too needs further investigation.
} 
Lynch, Michael (2013), “Three Questions for Truth Pluralism”, in N.J. Pedersen \& C. Wright (eds), Truth and Pluralism (Oxford: Oxford University Press), 21-41.

McLeod, Alexus (2007), "A reappraisal of Wang Chong's Critical Method through the Wenkong Chapter", Journal of Chinese Philosophy, 34 (4): 581-596.

- (2011), "Pluralism about Truth in Early Chinese Philosophy: a Reflection on Wang Chong's Approach", Comparative Philosophy, 2 (1): 38-60<http://www. comparativephilosophy.org>.

- (2012), "Wang Chong (Wang Ch'ung)", Internet Encyclopedia of Philosophy, $<$ http://www.iep.utm.edu/wangchon/>.

Mou, Bo (2009), Substantive Perspectivism: An Essay on Philosophical Concern with Truth (Dordrecht: Springer).

Schnieder, Benjamin (2006), "Truth-making without Truth-makers", Synthese 152: 21-46.

Wang Chong 王充, Lun-Heng 論衡, 〈http://ctext.org/Lun-Heng>.

Wheeler, Samuel (2014), Neo-Davidsonian Metaphysics: From the True to the Good (New York. Routledge).

Wright, Crispin (2001), "Minimalism, Deflationism, Pragmatism, Pluralism", in M.P. Lynch (ed.), The Nature of Truth (Cambriddge MA: MIT Press), 751-788. 